\title{
Value of contrast echocardiography in patient with advanced heart failure
}

\section{(1) Sandra Jakšić Jurinjak ${ }^{1 *}$, \\ (D)Mario Udovičić', (D)Boris Starčević1,2, (D)Petra Vitlov' (D) Jelena Kursar', DOgnjen Čančarević' , (D)Miroslav Raguž', (D)Hrvoje Falak', (i)Igor Rudež ${ }^{1,2}$}

University Hospital Dubrava Zagreb, Croatia

${ }^{2}$ University of Zagreb School of Medicine, Zagreb, Croatia

RECEIVED:

February 28, 2019

ACCEPTED:

March 24, 2019

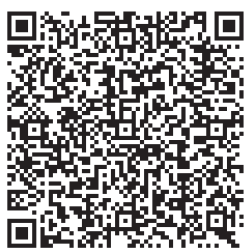

$\square$ Cardiologia Croatica 2019:14(3-4):60.
KEYWORDS: contrast echocardiography, cardiomyopathy, heart transplantation. CITATION: Cardiol Croat. 2019;14(3-4):60-1. | https://doi.org/10.15836/ccar2019.60

*ADDRESS FOR CORRESPONDENCE: Sandra Jakšić Jurinjak, Klinička bolnica Dubrava, Avenija Gojka Šuška 6, HR10000 Zagreb, Croatia. / Phone: +385-91-4374-456 / E-mail: sjaksicj@gmail.com

ORCID: Sandra Jakšić Jurinjak, https://orcid.org/0000-0002-7349-6137 • Mario Udovičić, https://orcid.org/0000-0001-9912-2179 Boris Starčević, https://orcid.org/0000-0002-3090-2772 • Petra Vitlov, https://orcid.org/0000-0001-6983-1409

Ognjen Čančarević, https://orcid.org/0000-0002-1285-8042 • Miroslav Raguž, https://orcid.org/0000-0003-1567-8503 Hrvoje Falak, https://orcid.org/0000-0002-6502-683X • Igor Rudež, https://orcid.org/0000-0002-7735-6721

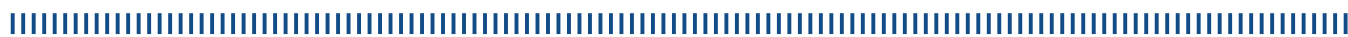

Introduction: Transthoracic echocardiography is still the diagnostic standard procedure in pre heart transplant and advanced heart failure diagnostics. Despite continued improvements in non-contrast echocardiography, image quality is sometimes suboptimal for assessing regional and segmental wall. ${ }^{1,2}$

Case report: 22-year-old patient suffering from dilative cardiomyopathy and diabetes mellitus type I presented with signs of severe dyspnoea and was admitted to intensive coronary unit due to acute heart failure. Dilative cardiomyopathy was verified with severely reduced ejection fraction to $15 \%$ of the left ventricle, with apical left ventricular thrombus, clinically NYHA IV stage, initially INTERMACS 3. The hypertrabeculation of left ventricular wall was indicating that the aetiology could be non-compaction cardiomyopathy. He was referred to our transplant centre, where complete pre-transplant work-up was conducted. Despite optimal medical therapy, clinical condition deteriorated, NT-
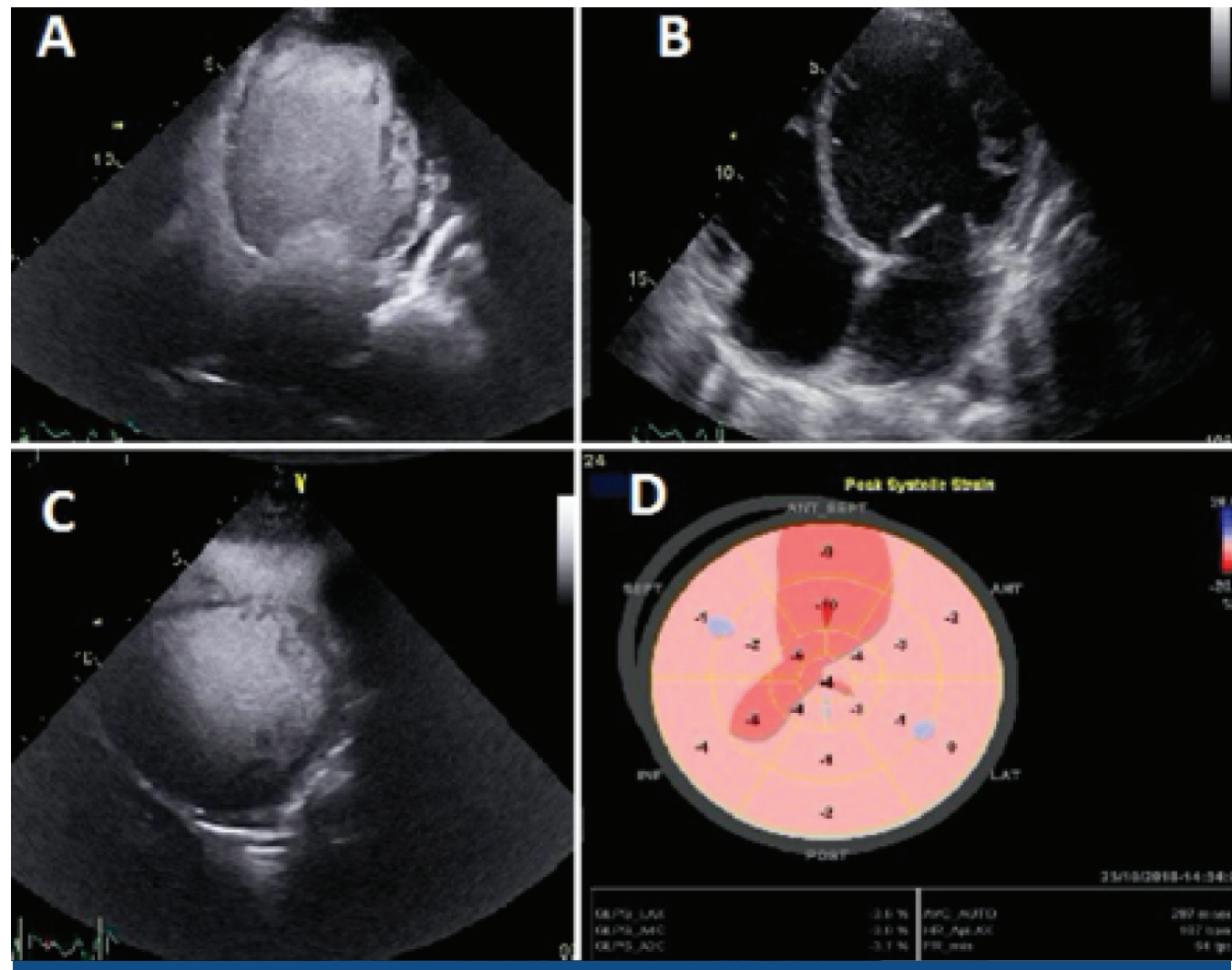

FIGURE 1. A, C. Left ventricular opacification showing trabeculated and dilated left ventricle indicating non-compaction cardiomyopathy, no presence of intracardiac thrombus. B. Dilated left ventricle in 4 chamber apical view. D. Bulls eye of left ventricular longitudinal strain showing diffuse poor longitudinal strain. 
pro-BNP measured up to 13122.9-pg/mL and he was on inotropic support, heart failure medication and anticoagulation therapy due to left ventricular apical thrombus. Right heart catheterization showed a moderate increase of pressures in pulmonary circulation due to congestion and his cardiac index calculated from right heart catheter was $1.48 \mathrm{~L} / \mathrm{min} / \mathrm{m}^{2}$. Coronary artery disease was excluded by coronary angiogram. Due to deterioration, the patient needed ECMO support, and finally the multidisciplinary heart transplant team decided to implant extracorporeal left ventricular assist device (LVAD). As it is paramount to be aver of left ventricular thrombus in case of LVAD implantation, the contrast echocardiography for opacification of the left ventricle (Optison GE Healthcare) was conducted excluding the thrombus in the left ventricle and showing the extent of left ventricular trabeculation (Figure 1). Finally, patient was transplanted after three weeks of extracardiac LVAD support and was discharged from hospital in good condition. As addition, it is interesting that a patient has twin brother without diabetes mellitus, and his echocardiographic report is suggestive of dilative cardiomyopathy -noncompaction but with far better left ventricular contractility and ejection fraction of LV of $35 \%$.

Conclusion: Use of contrast echocardiography to guide urgent treatment decisions in critically ill patients and making treatment decisions as in device therapy provides a valuable option for improving endocardial border resolution and outcome in these patients. rejection. Eur Heart J Cardiovasc Imaging. 2013 Dec;14(12):1187-94. https://doi.org/10.1093/ehjci/jet066

2. Zeisbrich M, Kihm LP, Drüschler F, Zeier M, Schwenger V. When is contrast-enhanced sonography preferable over conventional ultrasound combined with Doppler imaging in renal transplantation? Clin Kidney J. 2015 0ct;8(5):606-14. https://doi.org/10.1093/ckj/sfv070 